\title{
Antimicrobial Screening of Vanga Vennai and Mathan Thailam for Diabetic Foot Ulcer
}

\author{
Elangovan. $S^{1 *}$ Jeeva gladys. $\mathrm{R}^{2}$ Kalai arasi. $\mathrm{R}^{3}$ Mubarak. $\mathrm{H}^{4}$ Velpandian. $\mathrm{V}^{5}$ \\ ${ }^{1,2,3}$ PG Scholars, Dept. of Kuzhanthai Maruthuvam (Paediatrics), GSMC, Palayamkottai. \\ ${ }^{4}$ Senior Research Fellow (S), SCRU, Palayamkottai. \\ ${ }^{5}$ Lecturer, Dept. of Gunapadam (Pharmacology), GSMC, Chennai.
}

\begin{abstract}
Siddha medicine is one of the ancient traditional science which is specialized in external medicines (Pura marunthukal). Diabetic patients develop foot ulcers as a major complication of Diabetes mellitus due to high susceptibility to infection which often leads to amputation. Diabetic foot infection is a combination of both aerobic and anaerobic organisms. Thus there is a need for effective and selective treatment strategies. This article focuses on antimicrobial screening of Vanga vennai $(V V)$, Mathan Thailam $(M T)$ and combination of both $(V V+M T)$ which are the classical Siddha preparations. The methodology involved in the study is Agar well dilution method for anti microbial activity. Thus it paves a new way in treating infections of Diabetic foot ulcers. This preliminary study reveals these Siddha formulations as an effective therapeutic strategy for the management of Diabetic foot ulcer.
\end{abstract}

Keywords: Anti microbial activity, Diabetic foot ulcer, Mathan thailam, Siddha medicine, Vanga vennai.

\section{Introduction}

The diabetic foot ulcer is one of the well known complications for patients with diabetes mellitus. The diabetic foot, according to the International Consensus is an infection, ulceration or destruction of deep tissues associated with neurological and varying degrees of peripheral vascular disease in the lower extremities that affects the patients with diabetes mellitus. The diabetic foot is a serious health problem that is increasing year by year, which causes major health and socioeconomic impacts, altering the quality of life of patients.

The number of people with diabetes worldwide was estimated as 131 million in 2000 and it is expected to increase to 366 million by $2030^{[1]}$. Previous studies have indicated that diabetic patients have $25 \%$ life time risk for developing foot ulcers ${ }^{[2]}$. The percentage of diabetic foot ulcer may increase as much as $50 \%$ after 25 years of diabetes ${ }^{[3]}$. If untreated, Diabetes is the leading cause of nontraumatic amputations of the lower extremities in developed countries, and between $14 \%$ and approximately $24 \%$ of diabetic patients with foot ulcer should undergo amputation. Since diabetic ulcer is polymicrobial in nature and there is an increasing resistance to antibiotics in recent days, it necessitates the search for new compounds with potential effects against pathogenic bacteria. Most of the anti biotics available in modern medicine is effective against specific organism and resistance to other. Therefore an effort was made to evaluate the anti polymicrobial potential of Siddha formulations such as Vanga vennai (VV), Mathan thylam (MT) and the combination of both (VV+MT) comparatively against common pathogens of diabetic foot ulcer.

\subsection{Pathogenesis of Diabetic Foot Ulcer}

Peripheral neuropathy and ischemia from peripheral vascular disease are the two major causes of diabetic foot ulcers ${ }^{[4]}$.

\subsubsection{Peripheral neuropathy}

It is important to note that people with diabetes are more likely to develop symptoms associated with peripheral neuropathy as the hyperglycemia condition results in the intracellular conversion of glucose to sorbitol and fructose. This results in alteration of neuronal conduction which leads to lack of sensation in the lower extremities.

Ulcers are formed by a combination of factors, such as lack of sensation in the foot, poor circulation, foot deformities, irritation, trauma and prolong duration of diabetes. Patients suffering from diabetes for many years can develop neuropathy, which is the reduction or loss of sensation in the feet due to nerve damage caused by high blood glucose level over time. The person may unknowingly have the problem as the condition is painless. 


\subsubsection{Vascular Disease}

Peripheral arterial disease (PAD) usually refers to the filling of atherosclerosis in the arteries of the lower limbs and is one of the major cause for the development of foot ulcers in the lower extremities. Persistent hyperglycemic state results in endothelial cell dysfunction and smooth cell abnormalities in peripheral arteries ${ }^{[5]}$. A decrease in endothelium-derived vasodilators leading to vasoconstriction, increase in thromboxane A2, a vasoconstrictor and platelet aggregation agonist leads to plasma hypercoagulability ${ }^{[6]}$. This results in blockage of the artery which supplies the blood to the organs and muscles in the periphery, thereby reducing the supply of nutrients and oxygen and increases the risk of foot ulceration.

\subsection{IMPORTANCE OF THE STUDY}

As diabetic ulceration has been shown to end up in amputation up to $85 \%$ of cases, at least $40 \%$ of amputation in diabetic patients can be prevented with a team approach to wound care ${ }^{[7]}$. In diabetic patient even a small discontinuity in the skin can become a portal entry for bacteria. Prolonged infection with improper treatment leads to gangrene and amputations. Hence there is an urge to establish an effective therapeutic strategy for the treatment of diabetic foot ulcer to improve the quality of life of the affected individuals.

\subsection{Selection of the trial drugs}

\section{Materials and Methods}

The Siddha external medicine 'Vanga vennai' was prepared as per the Siddha classical text ${ }^{[8]}$ by grinding the powder of Vanga chenduram (red oxide of lead), Mirutharsingi (lead monoxide) both in equal proportion to which half the amount of Thurusu (Blue viterol -copper sulphate) added and ground with Vennai (butter). Mathan thylam was prepared as per classical text ${ }^{[9]}$ by mixing Umathai ilai charu (leaf juice of Datura alba) and Thenkai ennai (Coconut oil) in the ratio of 5:2. It is then boiled by adding 1/5 part of purified Thurusu (purified Copper sulphate) and filtered at proper consistency after the evaporation of water fraction (Fig.1a, 1b and 1c).

Vanga vennai (VV) and Mathan thylam (MT) traditional Siddha medicines from classical Siddha texts were selected for antimicrobial activity along with standard controls by Agar well dilution method.

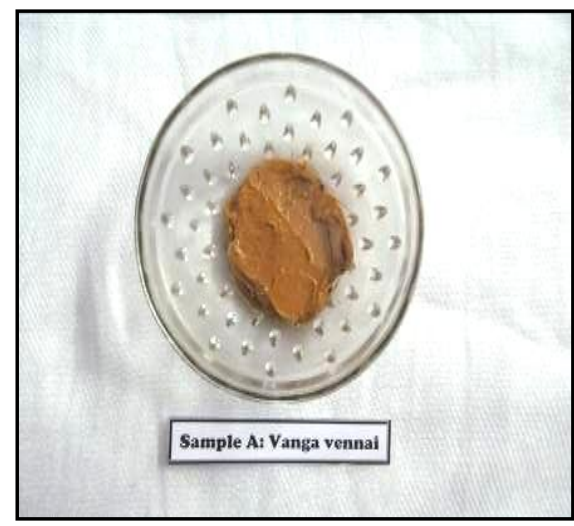

Fig No.1 a. Sample of Vanga Vennai

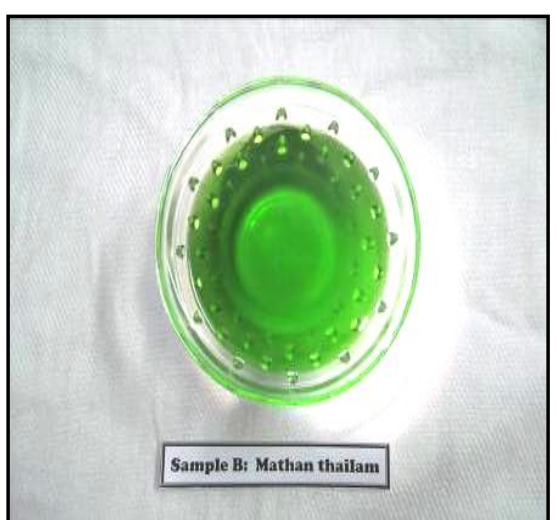

Fig No.1 b. Sample of Mathan Thylam

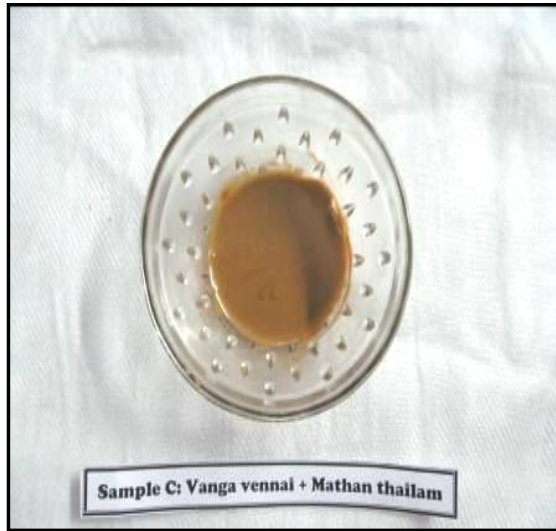

Fig No.1 c. Mixed Sample of Vanga Vennai and Mathan Thylam 


\subsection{Evaluation of Anti-Microbial Activity}

The organisms taken up for the study were Staphylococcus aureus, Klebsiella pneumoniae, Pseudomonas aeroginosa, Proteus mirabilis and Eschirichia coli which were obtained from a diabetic foot ulcer swab in a patient of Government Siddha Medical College Hospital, Palayamkottai, Tamilnadu and cultured in Mueller hinton broth at $37^{\circ} \mathrm{C}$ for 18 hours and then stopped at $4^{\circ} \mathrm{C}$ in Mueller hinton agar ${ }^{[10]}$. The Pathologic bacterial culture was inoculated into sterile nutrient broth and incubated at $37^{\circ} \mathrm{C}$ for 3 hours until the culture attained a turbidity of $0.5 \mathrm{Mc}$ Farland units and finally standardized to $10^{5} \mathrm{CFU} / \mathrm{ml}$.

\subsubsection{Preparation of disc:}

The drug samples were dissolved in the solvent ether. The sterile blotting paper disc $10 \mathrm{~mm}$ was soaked in the diluted solution. The amount of diluted solution absorbed by each disc was $5 \mathrm{mg}$ of each extract. The prepared discs were dried in controlled temperature to remove excess of solvent used in this study.

\subsubsection{Antibacterial activity using disc diffusion:}

The modified paper disc diffusion method ${ }^{[11-14]}$ was employed to evaluate the antibacterial activity of the Siddha external medicines. The inoculums were spread over the nutrient agar plate using a sterile cotton swab in order to get a uniform microbial growth. The prepared antibacterial discs were placed over the lawn and pressed slightly along with positive and negative controls Ampicilin 10mcg/disc and Ether respectively. The plates were incubated at $37^{\circ} \mathrm{C}$ for 18 hours and the diameter of zone of inhibition was measured (Table.1).

\section{RESULTS AND DISCUSSION}

The advantage of herbo mineral preparations is their stability over a period, easy storability and sustained availability. Herbs mixed with minerals and metals make them more effective against the target pathogens. It was observed that the sample A (Vanga vennai), Sample B (Mathan thylam) and Sample C (Vanga vennai+Mathan thylam) showed significant antimicrobial activity against the common pathogens of diabetic foot ulcer such as Staphylococcus aureus, Proteus mirabilis, Klebsiella pneumonia, Pseudomonas aeruginosa and Escherichia coli when compared to the standard antibiotic Ampicilin which is taken as positive control. The solvent ether taken as negative control shows no zone of inhibition. (Table-1 \& Fig.2). Sample A (VV) Showed higher zone of inhibition to Proteus mirabilis $(21 \mathrm{~mm})$ and Pseudomonas aeruginosa $(17 \mathrm{~mm})$. Sample B (MT) Showed higher zone of inhibition to Klebsiella pneumonia $(21 \mathrm{~mm})$ and Sample C (VV+MT) showed higher zone of inhibition to Staphylococcus aureus $(17 \mathrm{~mm})$, Proteus mirabilis $(20 \mathrm{~mm})$, Pseudomonas aeruginosa $(17 \mathrm{~mm})$ and Klebsiella pneumonia $(19 \mathrm{~mm})$. The present screening of Siddha formulation reveals that the sample $\mathrm{C}$ (Vanga vennai+Mathan thylam) showed good antibacterial activity against the tested pathogens of diabetic foot ulcer rather than using them individually (Fig.3).

Table.1 Anti bacterial activity of Vanga Vennai and Mathan Thailam

\begin{tabular}{|c|c|c|c|c|c|}
\hline \multirow{2}{*}{ SAMPLES } & \multicolumn{5}{|c|}{ Zone of inhibition in mm } \\
\cline { 2 - 6 } & $\begin{array}{c}\text { Staphylococcus } \\
\text { aureus }\end{array}$ & $\begin{array}{c}\text { Klebsiella } \\
\text { pneumonia }\end{array}$ & $\begin{array}{c}\text { Proteus } \\
\text { mirabilis }\end{array}$ & $\begin{array}{c}\text { Pseudomonas } \\
\text { aeruginosa }\end{array}$ & $\begin{array}{c}\text { Escherichia } \\
\text { coli }\end{array}$ \\
\hline $\begin{array}{c}\text { Sample A } \\
\text { (Vanga vennai) }\end{array}$ & 16 & 18 & 21 & 17 & 13 \\
\hline $\begin{array}{c}\text { Sample B } \\
\text { (Mathan } \\
\text { thailam) }\end{array}$ & 16 & 21 & 15 & 15 & 10 \\
\hline $\begin{array}{c}\text { Sample C } \\
\text { (Vanga vennai + } \\
\text { Mathan thailam) }\end{array}$ & 17 & 19 & 20 & 17 & 15 \\
\hline $\begin{array}{c}\text { Negative control } \\
\text { (Ether) }\end{array}$ & - & - & - & - & - \\
\hline $\begin{array}{c}\text { Positive control } \\
\text { (Ampicilin) }\end{array}$ & 26 & 24 & 23 & 21 & 20 \\
\hline
\end{tabular}


Antimicrobial Screening Of Vanga Vennai And Mathan Thailam For Diabetic Foot Ulcer

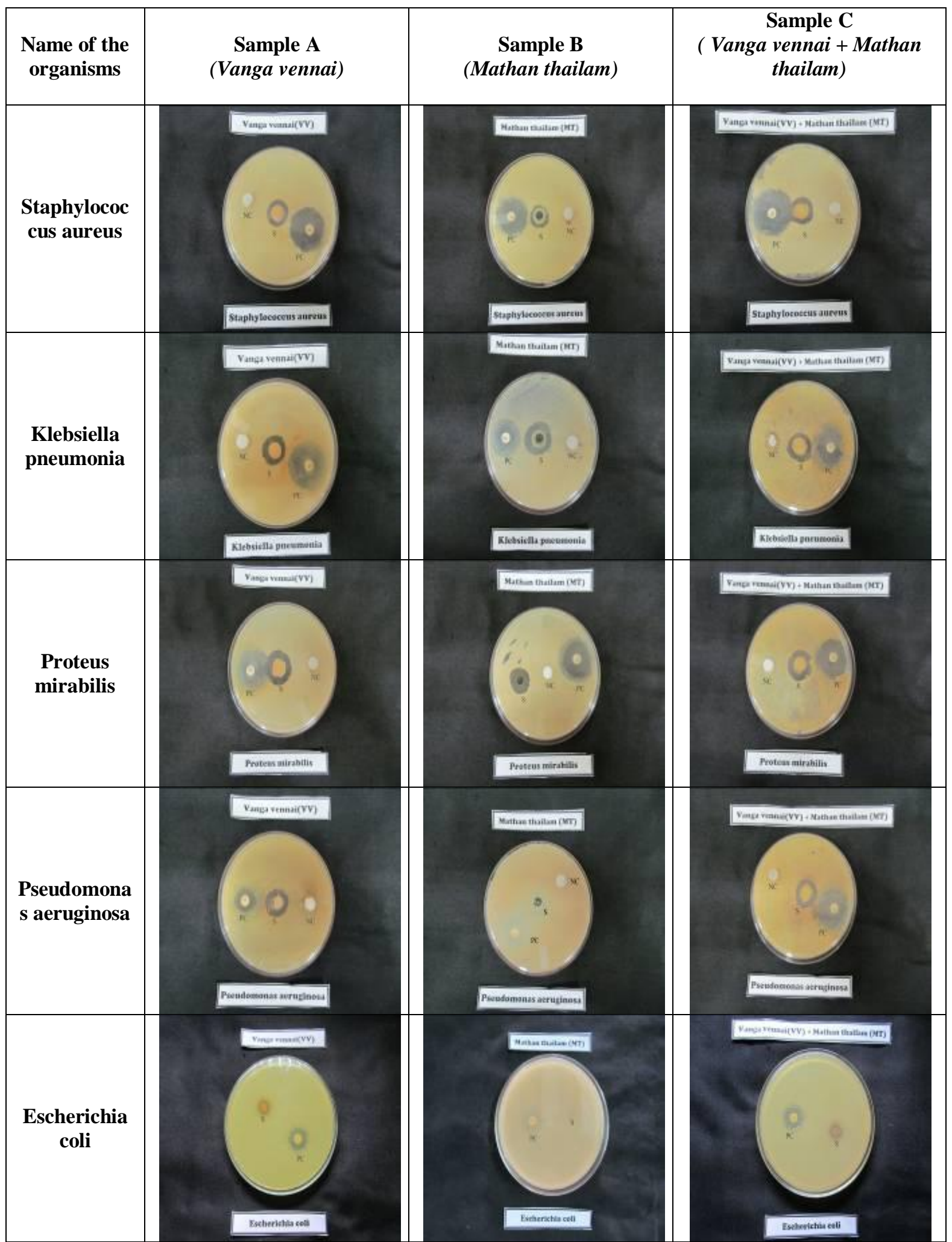

Fig No.2. Pictures showing the zone of inhibition 


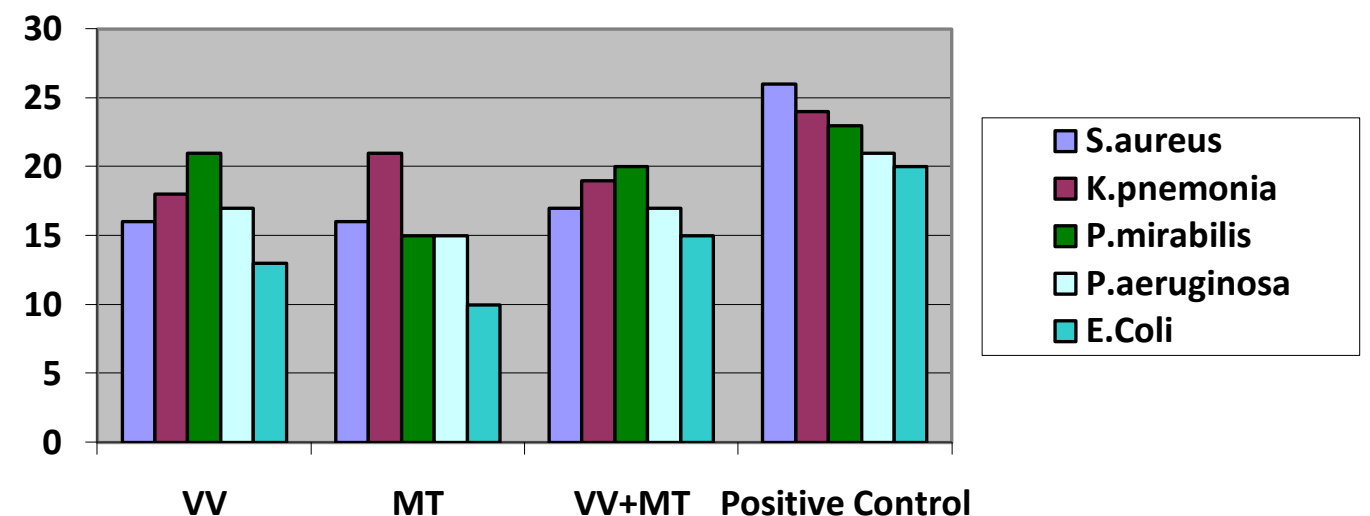

Fig.3 Anti bacterial action of the Sample Drugs

\section{Conclusion}

This present study can be concluded that the combination of Vanga Vennai and Mathan thylam showed the good anti microbial activity against various pathogens. Further evaluation of this drug is needed to establish the mechanism of action, pharmaco therapeutics, toxicity with proper standardisation and clinical trials. The initial study is promising to ensure wound healing properties and to prevent complications of diabetic foot ulcer successfully.

\section{Acknowledgement}

We thank Mr.A.Heber, Senior Clinical Scientist and Dr.G.Amala Rani, Microbiologist Dr Agarwal's Eye hospital, Tirunelveli, Dr. D.K. Soundara rajan and Dr.R.Lakshmi, Govt. Siddha Medical College, Palayamkottai for their suggestions.

\section{Reference}

[1]. Wild S, Roglic G, Green A, Sicree R, King H: Global prevalence of diabetes: estimates for the year 2000 and projections for 2030. Diabetes Care 27:1047-1053, 2004

[2]. Singh N, Armstrong DG, Lipsky BA: Preventing foot ulcers in patients with diabetes. JAMA 293:217-228, 2005

[3]. Levin ME, O’Neal LW, and Bowker JH, eds. The Diabetic Foot, 5th ed. St. Louis, Mosby Year-Book, 1993.

[4]. Bowering CK: Diabetic foot ulcers: pathophysiology, assessment, and therapy. Can Fam Phys 47:1007-1016, 2001

[5]. Zochodone DW: Diabetic polyneuropathy: an update. Curr Opin Neurol 21:527-533, 2008

[6]. Paraskevas KI, Baker DM, Pompella A, Mikhailidis DP: Does diabetes mellitus play a role in restenosis and patency rates following lower extremity peripheral arterial revascularization? A critical overview. Ann Vasc Surg 22:481-491, 2008

[7]. Warren clayton, Tom A.Elassy, A review of the pathophysiology, classification and treatment of foot ulcers in diabetic patients, Clinical diabetes spring 2009 vol27no:2 52-58

[8]. Kuppuswamy Mudhaliyar N.K, Uthamarayan K.S, Siddha Pharmacopoeia, Department of Indian medicine and Homeopathy, Chennai, page: 306

[9]. Thyagarajan.R, Siddha Materia Medica-Thaathu vaguppu, Department of Indian medicine and Homeopathy Chennai,4th edition, 2004, page: 555

[10]. Atlas, R.M. (2004). Handbook of Microbiological Media. London: CRC Press. p. 1226

[11]. British Society of Antimicrobial Chemotherapy. A guide to sensitivity testing: Report of working party on antibiotic sensitivity testing. J Antimicrob Chemother 27 (Suppl D):P. 1, 1991.

[12]. National Committee for Clinical Laboratory Standards. Performance Standards for Antimicrobial Susceptibility Testing. $8^{\text {th }}$ Informational Supplement. Villanova Pa, USA, ML100 S12, 2002.

[13]. Basic Laboratory Procedures in Clinical Bacteriology. $2^{\text {nd }}$ Edition. Eds. J. Vandepitte et al. World Health Organization, Geneva, 2003.

[14]. CLSI Clinical and Laboratory Standards Institute. Performance Standards for Antimicrobial Susceptibility Testing. Sixteenth Informational Supplement. Clinical and Laboratory Standards Institute, Chicago. Document M100-S16, 2006. 